\title{
Improving the absorptive capacity through unlearning context: An empirical investigation in Hospital-in-the-home units
}

\begin{abstract}
:
The Spanish health care system has undergone important changes, particularly in the development of new homecare services. In practice, however, results have been mixed. Some homecare services have been successful, but implementation failures are common and the intended patients are frequently reluctant to use the homecare services. A possible explanation for efficiency and effectiveness gaps of services provided by Hospital-in-the-Home Units may relate to the advantages and disadvantages of the knowledge processes that these units highlight as a result of their different structural properties. This study examines the impact of an unlearning context on the Hospital-in-the-home unit's ability to challenge of basic beliefs and to implement processes that are explicitly or tacitly helpful in the reception of new ideas (absorptive capacity). These relationships are examined through an empirical investigation of 54 doctors and 62 nurses belonging to 44 Hospital-in-the-Home Units (HHU). Our results show that the unlearning context plays a key role in managing the tension between potential absorptive capacity and realised absorptive capacity.
\end{abstract}

Keywords: Unlearning context, Hospital-in-the-home Unit, absorptive capacity. 


\section{Introduction}

Knowledge management is often referred to as organizational learning, organizational memory and expertise management (Swee, 2002). Traditionally, organizational knowledge needs to become a stable resource if it is to be translated into a profitable venue for information sharing. There is a growing rate of turnover among doctors, nurses, and/or knowledge workers who accumulate organization-specific knowledge that are ultimately lost to the healthcare system. Therefore, information needs to be captured, interpreted, and transferred into knowledge, which in turn that will continue to serve the healthcare organization, regardless of the individuals' original purpose for collecting the information.

The Hospital-in-the-Home Unit is an innovation which delivers acute hospital services to appropriate patients in their own homes (Montalto, 1996). Health care resources are limited, leading to a need to identify the true expense generators so as to be able to optimise resource use. The World Health Organization stresses that strategies should be drawn up for providing support to patients and carers at community level in order to avoid costly institutional care (e.g., Montalto, 1996; Drake \& Bethan, 2006). In this regard, the key benefits of Hospital-in-the-Home Units are clear. Whether the patient stays at home, hospital admissions decrease, and more importantly, infections are avoided (Planas-Miret et al., 2005).

The literature in the field of organizational learning reports that organizations that possess relevant prior knowledge are likely to have a better understanding and implement new ideas and develop new products and services (Tsai, 2001). Many scholars have suggested that the ability to exploit external knowledge is a critical 
component of organizational capabilities (Cohen \& Levinthal, 1990). A health unit's absorptive capacity is the enabling quality for converting knowledge into new products, services or processes to support innovation (Zahra \& George, 2002; Harrington \& Guimaraes, 2005; Newey \& Zahra, 2009). In the present paper, we focus on the distinction between what Zahra and George (2002) refer to as "potential absorptive capacity' and 'realised absorptive capacity'. While the term potential absorptive capacity is used to refer to the capacity to acquire and assimilate knowledge, the concept of realised absorptive capacity includes transformation and exploitation capabilities.

Although it seems intuitively clear that potential absorptive capacity provides support for realised absorptive capacity by supporting a broad range of potential responses (March, 1972), there is some ambiguity regarding the relationship between potential absorptive capacity and realised absorptive capacity (Zahra \& George, 2002). Potential absorptive capacity and realised absorptive capacity are fundamentally different concepts that require very different strategies and structures and the resulting tensions between the two are difficult to reconcile (Newey \& Zahra, 2009). While potential absorptive capacity requires change, flexibility and creativity, realised absorptive capacity requires order, control and stability. This means that potential absorptive capacity might also have a negative impact on realised absorptive capacity, which may well result in the under-utilization of relevant knowledge or the utilization of irrelevant knowledge, both of which are liable to lead to a degradation of innovation (Lyndon, 1989).

In this paper, we propose an unlearning context to manage an appropriate balance between potential absorptive capacity and realised absorptive capacity. At its heart, the 
unlearning context, attempts to reorientate organizational values, norms and/or behaviours by changing cognitive structures (Nystrom \& Starbuck, 1984), mental models (Day \& Nedungadi, 1994), dominant logics (Bettis \& Prahalad, 1995), and core assumptions which guide behaviour (Shaw \& Perkins, 1991) to attain a competitive advantage. In consequence, organizations should create an internal context where the newly generated knowledge can be valued and combined with existing knowledge in order to develop new products, services or processes. Therefore, the new, valuable knowledge for the firm can contribute to sustaining organizational performance in the following years.

All these dimensions are discussed in detail in the following section. The third section investigates the development of a model to explore how these dimensions contribute to cover the gap between potential absorptive capacity and realized absorptive capacity. Details of the survey, which was used to collect appropriate data with which to test the models is presented in the next section, whilst the results of testing the model are presented in the fifth section. This is followed by the discussion of those results.

\section{Linking potential absorptive capacity with realised absorptive capacity through unlearning}

Nowadays, knowledge is considered to be a valuable resource for the survival of organizations. A consolidated theory of organizational learning has underlined the advantages of the creation of new knowledge in organizations. However, new knowledge frequently generates internal problems when it contradicts current knowledge, behaviours or organizational routines. In this context, the presence of an internal environment that fosters the replacement of old knowledge could be essential 
for organizations that wish to create new products or services that require new points of view and ideas. Unlearning can be understood as a context where employees can change their habits and routines and forget old knowledge, and substitute new habits and knowledge, as part of a major process or which might be described as learning.

In recent organizational learning literature, the term unlearning has been analyzed in two related streams (i.e. individual forgetting and organizational un/relearning). Regarding individual forgetting, it is often stated that forgetting takes place at an individual level, since organizations themselves cannot forget (e.g. Imai et al, 1985; De Holan \& Philps, 2004; Cegarra \& Sánchez, 2008). Most authors refer to forgetting as challenging for individuals because of the loss of prior ways of seeing reality - the loss of fundamental assumptions - which until now had brought certainty and security (Akgün et al, 2007). This process may be facilitated by 'awareness' in the individual that there is a new way, along with the desire to 'relinquish old ideas' (Becker, 2005).

With regards to organizational un/relearning, drawing upon a reading of Sinkula (2002) and Akgün et al. (2003), Akgün et al. (2007) propose that organizational unlearning, in essence, is operationalized as changes of routines in the organization. Therefore, unlearning at the organizational level is viewed as memory elimination in general and as changing beliefs, norms, values, procedures, and routines in particular (Nonaka et al, 2001). A sudden change in those routines forces individuals to reconsider their old basic attitudes toward customers, competitors and suppliers (Sinkula, 2002).

In this study we have considered that unlearning (forgetting) takes place at the individual level, and therefore what happens at the organizational level is a change process as a consequence of the organizational relearning subsequent to individual 
unlearning (individual unlearning + organizational relearning $=$ organizational change). As Cegarra and Sanchez (2008) point out, relearning is an adaptation process where the new knowledge structures have to replace old knowledge structures, while individual unlearning is the art of forgetting. Put another way, while 'unlearning' is based on the premise that prior knowledge exists about a topic, idea, or concept and what we already know (explicitly and tacitly) and what we are trying to assimilate, interact and cross contaminate in non-linear and unpredictable ways (e.g. malicious gossips and rumours which support wrong assumptions exaggerations and partial truths), 'relearning' is based on the premise that unlearning is not always required and sometimes employees share rumours and gossips that complements existing knowledge structures (e.g. routines, procedures and processes).

The discussion above provides an illustration that the distinction between unlearning and relearning processes is not so clear (Tsang \& Zabra, 2008). As shown in Figure 1, this division is more pedagogic than structural. On the one hand, the processes are neither independent nor autonomous, but are constantly interacting. People are able to create new knowledge by both processes, and some researchers even go further and argue that unlearning flourishes within communities of learning and communities of practice (e.g. Mitchell \& Sackney, 2000; Wenger, 1998). From this perspective, unlearning can be understood as a necessary sub-process for relearning, but not all types of learning. As noted above, sometimes employees acquire new knowledge that complements existing routines, processes and procedures (i.e. relearning). In this vein, Sinkula et al. (1997) argues that workers relearn they also unlearn and new knowledge replaces old, forgotten routines.

The considerations set out above lead us to expect that unlearning could be a necessary 
task in the acquisition of new knowledge that is not compatible with current knowledge in hospitals. For example, what happens when a nurse has been using a similar tool for some years and the Hospital-in-the-home unit acquires a new one? In these circumstances, it would be a mistake to assume that whatever he/she knows is perfect; he/she may need to unlearn some habits and mindsets or he/she may need to take on other routines. As workers continue, familiarity and confidence are gained with the new tool, old ways of doing things recede, prior expectations fade, discomfort is reduced, and forgetting takes place. In this regard, Hospital-in-the-home units are constantly seeking for ways to improve their methods and ideas in order to improve the patient service (Cegarra \& Cepeda, 2010). That is why these units need a context where the oldest knowledge can be replaced (Rebernik \& Sirec, 2007).

\section{Place Figure 1 about here}

When attempting to explain the unlearning process, the 'unlearning context' and its different sub-dimensions are frequently cited as antecedents to the elimination of old logic at the individual level and the creation of room for new approaches at the organizational level. Chell (1993), for instance, used two models (i.e. acceptance of reality and adjustment) to explain the process through which individuals progress during change. French and Delahaye (1996) suggest a model of individual change involving four phases of security, anxiety, discovery and integration, in a cyclical and ongoing process of change adoption. Within this model, it is assumed that at various stages within the process, individuals are able to show a level of self-awareness, and will also experience a level of anxiety during the change process, "caused by the loss of old familiar patterns and processes”. Lewin's (1951) model of change involves three 
steps: a) unfreezing, which is suspending the current structure and involves disconfirmation of expectations, learning anxiety, and provision of psychological safety, b) transition, which is changing the mental structure and involves cognitive restructuring, semantic redefinition, and new standards of judgment; and c) refreezing, which is adapting the new mental structure and involves the creation of supportive social norms and making change congruent with personality. In the present paper, we have followed the suggestion of Cegarra and Sanchez (2008) that the unlearning context should be measured on three sub-dimensions, which clearly relate to Lewin's three steps:

(a) The examination of lens fitting, which refers to an interruption of the personnel's habitual, comfortable state of being, and the creation of a framework that enables individuals in an organization to have access to new perceptions.

(b) The framework for changing the individual habits, which refers to the challenge of inhibiting wrong habits when an individual has not only understood the new idea, but is motivated to make the change, and

(c) The framework for consolidating emergent understandings, which refers to the hospital processes that can free employees up to apply their talents by implementing new mental models based on adaptation to new knowledge structures.

The unlearning arguments outlined above seem to contradict absorptive capacity theory. In fact, absorptive capacity is the principle that assimilating new knowledge requires prior knowledge (Cohen \& Levinthal, 1990). Similarly, absorptive capacity can be conceptualised as a set of organizational abilities to manage knowledge, assimilate it, and apply it to their ends. Kim (1998) understands absorptive capacity as skills relating to the ability to learn and solve problems that enable an organization to assimilate 
knowledge and create new knowledge. A possible explanation of the difference between these two views of the role of prior knowledge may relate to the advantages and disadvantages of this knowledge in health organizations. As noted above, unlearning plays a crucial role when newly acquired knowledge is incompatible with previous organizational knowledge. Health organizations, which frequently develop new products and services, have to confront extremely dynamic environments, strong competition and rapid advances in technology, and these require the intensive use and updating of knowledge (Day, 1994; Slater \& Narver, 1995; Baker \& Sinkula, 1999; Sinkula, 1994; Tippins \& Sohi, 2003). A possible solution to this apparent dichotomy between unlearning and absorptive capacity may be found in an analysis of different absorptive capacity sub-dimensions.

Zahra and George (2002) have suggested four dimensions of absorptive capacity, each playing different but complementary roles in explaining how absorptive capacity can influence organizational performance. The first two dimensions (i.e. acquisition and assimilation) are in effect what Zahra and George (2002) label potential absorptive capacity (PACAP) and the other two dimensions (i.e. transformation and exploitation) constitute realised absorptive capacity (RACAP). Whereas PACAP implies personal internal processes such as reflection, intuition and interpretation, RACAP reflects the efficiency of leveraging externally absorbed knowledge. In other words, PACAP is considered a promising component in understanding and assimilating a new methodology (Purvis et al., 2001). When members of an organization have significant specialist experience and expertise, it is easier for them to make use of new knowledge about this specialism (Balogun \& Jenkins, 2003). Therefore, PACAP includes mental shortcuts about people, places, and things (stereotypes); how the world is and what is possible and not possible (mental models); and grooves and patterns of thinking about 
how things should be seen and what outcomes are likely (mindsets). In contrast with this, RACAP incorporates the combination of existing and newly acquired knowledge into operations.

Although, most studies in the area of absorptive capacity emphasise that RACAP is driven by PACAP (e.g. Zahra \& George, 2002; Cohen \& Levinthal, 1990), the existing literature has paid little attention to how RACAP is created and developed in the company. The few studies that have included organizational characteristics (e.g. Lane \& Lubatkin, 1998; Gupta \& Govindarajan, 2000) call for further research on the learning capacities of organizational units, organizational mechanisms to reduce the gap between what we are able to do (PACAP) and what we finally put into practice (RACAP). This gap can be seen when individuals are confronted with a substantial difference between what they see or hear and how they believe the world to be (Purvis et al., 2001). The negative impacts of flawed mental models (in terms of emotional states of confusion, helplessness, and intense anxiety) on decision-making have been discussed by several authors (Toft \& Reynolds, 1994; Reason, 1997; Chapman \& Ferfolja, 2001). In this framework, what individuals have already learnt to absorb (PACAP) may be extremely difficult to unpack and undo, as a wide variety of factors, such as fear of the unknown, mental shortcuts, lack of awareness or organizational structures that channel information through managerial pathways, contribute to the resistance individuals offer to attempts to alter what they do and how they do it. As Tripsas \& Gavetti (2000) highlight, experience significantly influences managerial cognition, which eventually determines an organization's ability to manage knowledge. Thus, a firm's PACAP is a path-dependent capability that is influenced by its prior knowledge and the past experiences of its members that are internalized as routines (Balogun \& Jenkins, 2003). These routines represent a mix of structure and agency and discussions of the traps of 
routinization tend to overemphasize structural rigidity and ignore the capacity of organizational members to 'think outside the box' of their cognitive myopia (HowardGrenville, 2005), which in turn causes RACAP to be undervalued (Lyndon, 1989). In order to develop RACAP, the ideas set out above could mean that organization (i.e. hospitals), in order to innovate, have to eliminate old logics and routines that have not only become outdated (Barr et al, 1992), but also continue to surface unexpectedly and hinder the transformation of PACAP into RACAP.

Therefore, although a learning process may promote acquisition, diffusion, transformation and exploitation of knowledge, and contribute to both potential and realized absorptive capacity, an unlearning context is necessary for the proper use of newly acquired knowledge, in order that it should be applied, and not rejected or ignored. The unlearning context is not only a mechanism for forgetting old knowledge, but is also the way companies are able to develop and make room for new knowledge (e.g. Huber, 1991; Bogenrieder, 2002; Nystrom \& Starbuck, 1984; Day \& Nedungadi, 1994; Bettis \& Prahalad, 1995; Shaw \& Perkins, 1991). In the examination of lens fitting and the framework for changing the individual habits, all the old logics and mental shortcuts are identified and reshaped with new understandings. The framework for consolidating emergent understandings may take relearning into the organization more generally, breaking barriers of group inertia and peer group pressure to build new critical norms and a critical mass capable of exerting force on the whole system to change its prescribed routines. As a consequence, an unlearning context, especially for innovative activities, plays a mediating role between new knowledge and previous, obsolete knowledge. Reduction of competition between the old and the new knowledge is helpful for personnel who have used the old knowledge in the past for the current operations. Through a reflective process, organizations can renew knowledge and 
generate organizational routines and behaviours that ensure a competitive advantage. This consideration allows us to frame the hypothesis of the present work:

Hypothesis: The impact of potential absorptive capacity on realised absorptive capacity is positively mediated through the unlearning context.

Figure 2 shows the sequential model which illustrates the proposed hypothesis.

Insert Figure 2 about here

\section{Method}

\section{Data collection}

In order to contrast the above hypothesis, the Hospital-in-the-home units (HHU) of Spain were considered. The Hospital-in-the-Home domain was chosen for two main reasons. On one hand, despite patient satisfaction being reported as being high in Hospital-in-the-Home (see Cleary et al., 1991), evaluation of the causes of high levels of satisfaction have been underdeveloped. On the other hand, the Hospital-in-the-Home Unit is an ideal platform to learn, because two or more individuals (e.g. patients, carers, doctors and nurses) are working together with different resources and complementary capacities, which are learning facilitator factors (Fenwick, 2007). In practical terms, this has shown the seed for knowledge to be made available and for Hospital-in-the-Home Unit members to be actively directed towards the patient in the form of strategic 
competence mapping, development and utilization.

Therefore, the Hospital-in-the-Home sector is an appropriate setting for an investigation of unlearning context and its impact on absorptive capacity. This is mainly because these units provide 'face-to-face' interaction allowing the exchange of information inserted into the social context of the patients, which by its tacit character is more difficult to imitate. This means being constantly searching for new ways to improve homecare services, developing new offerings and introducing improved working methods, but they will only occur if practitioners, careers and patients are engaged to share individual expertise and create organizational knowledge (Montalto, 1996). Consequently, HHU are highly motivated to introduce relationships with careers and patients to create knowledge and try to systematize the absorptive processes.

A list of HHUs provided by the National College of Practitioners (NCP) was used as an initial sampling frame combined with a similar list provided by the Spanish Homecare Society and 65 HHUs were considered for the research. Those units were contacted by the Spanish Homecare Society and asked to participate in the study and 44 agreed. They were also informed by telephone of the work objectives and they were assured its strictly scientific and confidential character as well as the global and anonymous treatment of the data. Finally, prior to the telephone interviews a presentation of the study was done in the 8th National Conference on Internal Medicine held on 18th-21st November 2009 in Valencia, Spain.

Surveying took place over a period of two months, from December 2009 to January 2010. Participants were divided into two categories: HHU members with nursing backgrounds and HHU members with medical backgrounds. In total, 63 nurse managers 
and 63 medical managers were telephoned and invited to participate in the study, and a total of 119 questionnaires were collected, of which 2 were found to be without an overall satisfaction rating. Therefore, data analysis was based on 117 valid questionnaires (55 doctors and 62 nurses). The great majority of respondents were female (62.1 percent) and had medical backgrounds (34.7 percent).

\section{Measures}

The questionnaire was designed based on the review of the literature described in Section 2. We modelled 'PACAP', 'unlearning context' and 'RACAP' as formative second-order constructs. We measured 'PACAP' and 'RACAP' by two first-order factors or dimensions: acquisition and assimilation; and transformation and exploitation respectively. We assessed the 'unlearning context' using three first-order factors or dimensions: 'consolidation of emergent understandings', 'the examination of lens fitting', and 'the framework for changing individual habits'. A question that arises when taking a multidimensional approach (i.e. using second-order measures) is whether these constructs (potential absorptive capacity, unlearning context and realised absorptive capacity) should be modelled as consisting of reflective or formative indicators. Indeed, understanding the underlying essence of the construct, whether it is reflective (i.e., changes in the underlying construct cause changes in the indicators) or formative (i.e., indicators impact or cause the underlying construct), is an essential first step in modelling its structure (MacKenzie et al. 2005). Therefore, the choice depends primarily on whether the first-order factors or dimensions are viewed as indicators or causes of the second-order factors (Chin, 1998). We chose to view the structure as formative for our three second-order constructs. In this way, an increase in the level of each dimension does not imply an increase in the level of the other dimensions. The 
dimensions are not necessarily correlated, and consequently traditional reliability and validity assessment have been dismissed as inappropriate and illogical for a formative second-order factor, with reference to its dimensions (Bollen, 1989).

This study mainly used existing scales taken from the literature. The questionnaire items are given in full in the Appendix. The questionnaire constructs comprised:

a) Potential and realised absorptive capacity (PACAP and RACAP). To examine potential and realised absorptive capacity, we sought to measure the dimensions that have been defined (Zahra \& George, 2002). Items were measured using a 7-point Likert scale from the study by Jansen et al. (2005). PACAP consists of two dimensions: acquisition and assimilation of new external knowledge. Six items assessed the intensity and direction of efforts expended in knowledge acquisition. In addition, four items measured assimilation and gauged the extent to which firms were able to analyze and understand new external knowledge. Ultimately, after a data cleansing process, 3 and 3 items formed the acquisition and assimilation scales respectively. RACAP includes the transformation and exploitation of new external knowledge. Six items initially measured transformation and assessed the extent to which firms were able to facilitate recognition of the opportunities and consequences of new external knowledge for existing operations, structures, and strategies (Zahra \& George, 2002). Six items tapped into the extent to which firms were able to exploit new external knowledge. The scale gauged the ability of companies to incorporate new external knowledge into their operations. The final cleansed scale consists of 3 items for both the transformation and exploitation dimensions.

b) Unlearning context. As described above, three-dimension form the unlearning context: 'consolidation of emergent understandings', 'the examination of lens fitting', 
and 'the framework for changing individual habits'. The measures relating to 'consolidating the emergent understandings' consisted of 6 items taken from a scale designed by Cegarra \& Sanchez (2008) and adapted from Akgun et al. (2007). These items describe the way management faced up to change, actively introduced it into the company through projects, collaborated with other members of the organization, and recognised the value of new information or taking risks. To measure the 'examination of lens fitting' 5 items were used. These items recognise the support of policies, rules, reporting, structures and decision-making protocols that encourage the identification of problems, mistakes and new ways of doing things. Finally, we measured 'the framework for changing individual habits' using 7 items. This scale focuses on employees' self-awareness or their own mistakes, ways of thinking and wrong behaviour that guide everyday attitudes.

Because the use of a single survey for data collection created the potential for commonmethod bias, we took a number of steps to minimize bias (Podsakoff et al., 2003). Procedural remedies are recommended when including formative constructs. We used the procedural remedies of protecting respondent anonymity and reducing apprehension by assuring subjects that there were no right or wrong answers, improving scale items with the input of an expert panel, and randomizing question order.

\section{Data analysis}

PLS was selected because of the characteristics of our model and sample data. Our model uses formative indicators and our data is non-normal. Other techniques of structural equation modelling (e.g. the covariance-based model performed by LISREL or AMOS) cannot be applied in these circumstances (Diamantopoulos \& Winklhofer, 
2001). In addition, PLS method is a structural equation modelling technique that generalizes and combines features from principal component analysis and multiple regression (Abdi, 2003; Chin, 1998). It originated in the social sciences (specifically economy, Herman Wold 1966) but became popular first in chemometrics (i.e., computational chemistry). PLS is a useful method for forming prediction equations when there are a large number of explanatory variables, particularly when the random error variance is large (Garthwaite, 1994).

Further, PLS can be a powerful method of analysis because of the minimal demands on measurement scales (i.e., do measures need to be at an internal or ratio level?), sample size, and residual distributions (Wold, 1985). Although PLS can be used for theory confirmation, it can also be used to suggest where relationships might or might not exist and to suggest propositions for testing later (Chin, 1998). Compared to the betterknown factor-based covariance-fitting approach for latent structural modelling, the component-based PLS avoids two serious problems: inadmissible solutions and factor indeterminacy (Fornell \& Bookstein, 1982). Because the iterative algorithm performed in a PLS analysis generally consists of a series of ordinary least squares (OLS) analyses, identification is not a problem for recursive models nor does it presume any distributional form for measured variables. The utility of the PLS method has been documented elsewhere (Falk \& Miller, 1992) as possibly more appropriate for a large percentage of the studies and data sets typically used among researchers (Chin, 1998)

This study uses PLS-Graph software version 03.00 Build 1058 (Chin, 2003). Using PLS involves following a two-stage approach (Barclay et al., 1995). The first step requires the assessment of the measurement model. This allows the relationships between the observable variables and theoretical concepts to be specified. This analysis is performed 
in relation to the attributes of individual item reliability, construct reliability, average variance extracted (AVE), and discriminant validity of the indicators of latent variables. In the second step, the structural model is evaluated. The objective of this is to test the extent to which the causal relationships specified by the proposed model are consistent with the available data. For hypothesis testing, we used the bootstrapping procedure recommended by Chin (1998).

To analyze the relationships between the different constructs and their indicators, we have adopted the latent model perspective, in which the latent variable is understood to be the cause of the indicators and, therefore, we refer to reflective indicators for firstorder constructs or dimensions. All constructs; 'potential absorptive capacity', 'realised absorptive capacity' and 'unlearning context', are modelled as second-order formative constructs.

With regard to the measurement model, we began by assessing the individual item reliability (Table 1). The indicators exceed the accepted threshold of 0.707 for each factor loading (Carmines \& Zeller, 1979).

Insert Table 1 about here

From an examination of the results shown in Table 2, we can state that all of the constructs are reliable. They have values for both Cronbach's alpha coefficient and for a composite reliability greater than the value of 0.7 required in the early stages of research, and the stricter value of 0.8 required for basic research (Nunnally, 1978). The 
AVE should be greater than 0.5 , meaning that $50 \%$ or more variance of the indicators should be accounted for (Fornell \& Larcker, 1981). All constructs of our model exceed this condition (Table 2). For discriminant validity, we have compared the square root of the AVE (i.e., the diagonals in Table 2) with the correlations among constructs (i.e., the non-diagonal elements in Table 2). On average, each construct relates more strongly to its own measures than to others.

Insert Table 2 about here

The evaluation of formative dimensions of three high-order constructs, 'potential absorptive capacity', 'realised absorptive capacity' and 'unlearning context', is different from that of the reflective dimensions. The appropriate procedure for formative dimensions is an examination of the weights (Mathieson et al, 2001), which is a canonical correlation analysis and provides information about how each indicator contributes to the respective construct (see Table 3). Weights do not need to exceed any particular benchmark because a census of indicators is required for a formative specification (Diamantopoulos \& Winklhofer, 2001). The concern with formative dimensions is potential multicolinearity with overlapping dimensions, which could produce unstable estimates (Mathieson et al., 2001). Results of a colinearity test show the variance inflation factor (VIF) scores of each second-order construct for all dimensions are far below the commonly accepted cut-off of 10. In addition, we confirmed the validity of the formative dimensions using the procedures suggested by Fornell \& Larcker (1981) and McKenzie et al (2005). 
Insert Table 3 about here

\section{Results}

The structural model resulting from the PLS analysis is summarised in Figure 3, where the explained variance of endogenous variables $\left(\mathrm{R}^{2}\right)$ and the standardised path coefficients $(\beta)$ are shown. As can be seen, all the hypothesized relationships are significant, and therefore, the hypothesis is supported. Since PLS makes no distributional assumptions in its parameter estimation, traditional parameter-based techniques for significance testing and modelling were used (Chin, 1998). One consequence of the comparison between covariance structure analysis modelling approaches and PLS is that no proper overall goodness-of-fit measures exist for models using the latter (Hulland, 1999). The structural model is evaluated by examining the $\mathrm{R}^{2}$ values and the size of the structural path coefficients.

Insert Figure 3 about here

The stability of the estimates is examined by using the t-statistics obtained from a bootstrap test with 500 resamples. Table 4 sets out the model statistics, the path coefficients and the $t$ values observed with the level of significance achieved from the bootstrap test. 
Insert Table 4 about here

Adopting the approach used by Tippins \& Sohi (2003), we checked for the presence of a mediating effect by comparing the direct effect between variables and the competing link where the mediated variable is inserted, in which two substantive links are estimated and evaluated for significant differences. Table 4 shows the results of the two competing links.

The first link (direct effect) examined the direct relationship between PACAP and RACAP, while the second link (partial mediation) examined the same relationship with the unlearning context acting as a mediator. The results of this partial mediation link support our hypothesis. Firstly, the partial mediation model explains more variance in RACAP than the direct effect model (0.48 vs. 0.40). Secondly, positive relationships exist between PACAP and the unlearning context $(\beta=0.670, p<0.001)$ and between the unlearning context and RACAP $(\beta=0.371, p<0.005)$ (see Figure 2). Thirdly, the significant relationship between PACAP and RACAP in the direct effect model $(\beta=$ 0.633, $\mathrm{p}<0.001)$ diminishes in the partial mediation model $(\beta=0.370, \mathrm{p}<0.005)$. Together, these three points provide evidence that there is a discernible mediating effect on the unlearning context and that the partial mediation model represents a significant improvement over the direct effect model. The partial mediation model explained a substantial amount of the variance of the realised absorptive capacity $\left(\mathrm{R}^{2}=0.48\right)$. We also estimate the ratio $\mathrm{F}^{2}$ suggested by Chin (1998), to provide the level of significance of the improvement. When $\mathrm{F}^{2}$ is greater than 0.02 , the improvement is significant. In our case $\mathrm{F}^{2}$ was 0.15 . 
Therefore, we can state that our hypothesis is supported. That is to say, the dependent variable (i.e. RACAP), is better explained in the presence of the mediator variables than when the mediators are not present. Finally, we performed the Stone-Geisser test for predictive relevance to assess model fit in the PLS analysis (Geisser, 1975; Stone, 1974). When q-squared is greater than zero, the model has predictive relevance. In our model, q-squared was 0.31 .

\section{Discussion}

Today, more than ever, the factors that define the nature and structure of the Spanish healthcare environment (e.g. demand, costs, system deregulation) are undergoing rapid change (Madorran-García \& de Val-Pardo, 2006) thus obliging hospital administrators to develop and implement flexible and adaptive services in order to survive in the

increasingly challenging environment facing hospital management. However, for a number of reasons the implementation of a new health service requires that health care practitioners learn new ways of acting and therefore be able to eliminate (forget, relearn) existing knowledge (e.g. Rushmer \& Davies, 2004). If we accept these suggestions then it is reasonable to infer that new health services will be unable to (or find it very challenging to) change its procedures and routines if it has not previously supported the revision and updating the existing knowledge and knowledge structures of individual practitioner's involved with the new health services.

The purposes of this study are to examine the relationship between absorptive capacity and potential contexts that can act as catalysts for this capacity. In pursuing those aims, we unpack the concept of absorptive capacity by capturing the processes behind the 
development of acquisition, assimilation, transformation and exploitation capacities, in the context of unlearning. As expected, and consistent with our model, organizational mechanisms associated with PACAP had a significant positive effect on RACAP. Therefore, if the PACAP-enhancing activities provide access to more knowledge, and a greater knowledge base enables the company to search for solutions more effectively, then these activities should improve the efficiency of RACAP (Cohen and Levinthal, 1990).

Furthermore, the organizational mechanisms associated with the unlearning frameworks provide somewhat surprising results. Our data indicate that PACAP has an indirect effect on RACAP through the unlearning context. This confirms what authors such as Zahra \& George (2002) suggested when they stressed that PACAP and RACAP are fundamentally different concepts that require very different strategies and structures, and that the resulting tensions between the two are difficult to reconcile. While PACAP requires change, flexibility and creativity, RACAP requires order, control and stability (Zahra \& George, 2002). Current measures may pay too much attention to the ability to recognise and assimilate external knowledge (i.e. PACAP) while neglecting the role of the receiving unit's motivation to put knowledge to health use (i.e. RACAP). Therefore, managers need to be aware of the role of the unlearning context in closing the knowledge gap between PACAP and RACAP. Because old, outdated knowledge can impede adaptation to new configurations, senior managers need to create a culture of continuous unlearning. Without care, organizations can fall into a 'competence trap' (Leonard-Barton, 1992), increasingly exploiting obsolete competences, or they can fall into a 'failure trap' (Levinthal \& March, 1993), where a failure while exploring new opportunities may lead to more research and change, and so to failure again, which leads to more research and so on. Taking this into consideration, we argue that the 
HHU's unlearning context plays a key role in managing the tension between PACAP and RACAP. As HHU members pursue new learning, the unlearning context is instrumental in establishing new habits, patterns and ways of doing things and interpreting things as integral to personnel's jobs.

This article makes an important contribution to the health management literature. Our results indicate that establishing an unlearning context, whereby an health organization encourages individuals to make their own choices as to how they divide their time between PACAP and RACAP, is possible. This finding is important in the ongoing debate surrounding the relationship between the exploration and exploitation of knowledge, and confirms what authors such as Eisenhardt \& Martin (2000) and Newey \& Zahra (2009) say when they argue that a organization's ability to reconfigure the dynamic processes of exploration and exploitation of knowledge is a key source of its sustainable competitive advantage. Consequently, this model presented in this paper provides practical steps for health managers interested in organizational structures that support knowledge processes.

\section{Conclusions}

As competition intensifies and the pace of change accelerates, it is likely that aspects of PACAP and RACAP will change over time, requiring the modification of some of the content of organizational learning. The present study found that the unlearning context mediates the effects of PACAP on RACAP. Although this result needs further investigation, one conclusion that might be drawn is that health managers need to foster an unlearning context to encourage the alignment of knowledge exploitation and exploration within the Hospital units, in order to build effective innovations. As part of 
this assessment, the results emphasise the need for health managers to have an explicit understanding of how their critical knowledge can be leveraged to renew their RACAP when needed. Perhaps management is over-investing in the development of PACAP and RACAP processes when they should be investing in mechanisms to facilitate the context of unlearning. Increased efforts to promote unlearning will greatly strengthen the link between PACAP and RACAP.

Future research will need to continue developing tools to support unlearning. Because knowledge entails scope and context and is enacted through the perspectives of multiple holders of knowledge in a firm and captured through language, the choice of the "holders of knowledge" who will identify what the firm must know is crucial (Cepeda \& Vera, 2007). The present study has relied on members of HHU teams as key holders of knowledge about the HHU unit and its capacity to learn or unlearn. Future research, might profitably sample multiple holders of knowledge within a hospital, and will be helpful in testing for inter-rater reliability and improving the internal validity of knowledge management studies. Furthermore, the present research was conducted within one national context to control for national culture effects across units. Nonetheless, this design affects the external validity of the results. Some relevant features of the units in this study need to be taken into consideration: (1) the units are relatively small and young, (2) most of the personnel hold a university degree, and (3) the technological environment is changing continuously. Future studies could compare our results with those in other contexts.

Finally, the cross-sectional design does not allow us to observe the short- and long-term impact of absorptive capacity on the unlearning context. Although our model proposes sequenced relationships between absorptive capacities (PACAP and RACAP) and the 
unlearning context, we measure all these constructs at one point in time. Also, our measures do not directly capture dynamic change in innovation, but only the positive association between PACAP, RACAP and unlearning context at one point. This positive association is suggestive of how a change in one variable is related to change in the other variable. Given the dynamic nature of the processes and constructs implied in our model, and the possibility of feedback loops and circular relationships characteristic of such dynamic capabilities, our study would benefit from a more longitudinal approach in order to understand more fully the link between unlearning context and absorptive capacities.

\section{References}

Abdi, H. (2003). Partial Least Squares Regression, Encyclopedia of Social Sciences Research Methods. Thousans Oaks: Sage

Akgün, A. E., Byrne, J. C., Lynn, G. S., \& Keskin, H. (2007). Organizational unlearning as changes in beliefs and routines in organizations, Journal of Organizational Change Management, 20(6), 794-812.

Akgün, A. E., Lynn, G. S., \& Byrne, J. C. (2003). Organizational learning: A sociocognitive framework, Human Relations, 56(7), 839-868.

Baker, W. E., \& Sinkula, J. M. (1999). The synergistic effect of market orientation and learning orientation on organizational performance, Journal of Academy of Marketing Science, 27(4), 411-427.

Balogun, J., \& Jenkins, M. (2003). Re-conceiving change management: A knowledgebased perspective, European Management Journal, 21(2), 247-257.

Barclay, D., Higgins, C., \& Thompson, R. (1995). The partial least squares (PLS) approach to causal modelling: Personal computer adoption and use as an illustration, Technological Studies, 2(2), 285-309.

Barr, P., Stimpert, J., \& A., H. (1992). Cognitive change, strategic action and organizational renewal, Strategic Management Journal, 13(SI), 15-36.

Becker, K. (2005). Individual and organizational unlearning: Directions for future research, International Journal of Organisational Behaviour, 9(7), 659-670.

Bettis, R. A., \& Prahalad, C. K. (1995). The dominant logic: Retrospective and extension, Strategic Management Journal, 16(1), 5-14.

Bogenrieder, I. (2002). Social architecture as a prerequisite for organizational learning, Management Learning, 33(2), 197-216.

Bollen, K. A. (1989). Structural equations with latent variables, Wiley, New York.

Carmines, E. G. \& Zeller, R. A. (1979). Reliability and validity assessment, Sage, 
London.

Cegarra, J,G. \& Cepeda, G. (2010). How to implement a knowledge management program in hospital-in-the-home units. Leadership in Health Services, 23(1), 46-56 .

Cegarra, J. G., \& Sánchez, M. T. (2008). Linking the individual forgetting context with customer capital from a seller's perspective, Journal of the Operational Research Society, 59(12), 1614-1623.

Cepeda, G., \& Vera, D. (2007). Dynamic capabilities and operational capabilities: A knowledge management perspective, Journal of Business Research, 60(5), 426437.

Cleary, P., Edgman-Levitan, S., \& Roberts, M. (1991). Patients evaluate their hospital care. Health Affairs, 10(4), 254-267.

Cohen, W. M. \& Levinthal, D. A. (1990). Absorptive capacity: A new perspective on learning and innovation, Administrative Science Quarterly, 35(1), 128-154.

Chapman, J. A., \& Ferfolja, T. (2001). The acquisition of imperfect mental models and their use in hazardous situations, Journal of Intellectual Capital, 2(4), 398-409.

Chell, E. (1993). The Psychology of behaviour in organizations, The Macmillan Press Ltd, London.

Chin, W. W. (1998). The partial least squares approach to structural equation modeling. In: G. A. Marcoulides (ed.) Modern Methods for Business Research (pp. 295336). Mahwah, NJ: Lawrence Erlbaum Associate.

Chin, W. W. (2003). PLS-Graph (Version 03.00, Build 1058) (Computer software), University of Houston.

Day, G. S. (1994). The capabilities of the market-driven organizations, Journal of Marketing, 58, 37-52.

Day, G. S., \& Nedungadi, P. (1994). Managerial representations of competitive advantage, Journal of Marketing, 58(4), 31-44.

De Holan, P., \& Philps, N. (2004). The remembrance of things past? The dynamics of organizational forgetting, Management Science, 50(11), 1603-1613.

Diamantopoulos, A. \& Winklhofer, H. (2001). Index construction with formative indicators: An alternative to scale development, Journal of Marketing Research, 38(2), 269-277.

Drake, P.R., \& Bethan, M.D. (2006). Home care outsourcing strategy. Journal of Health Organisation and Management, 20(3), 175-193.

Eisenhardt, K. M., \& Martin, J. A. (2000). Dynamic capabilities: What are they?, Strategic Management Journal, 21(10-11), 1105-1121.

Falk, R. F., \& Miller, N. B. (1992) A Primer for Soft Modeling. Akron, Ohio: The University of Akron Press.

Fenwick, T. (2007) Knowledge workers in the in-between: network identities. Journal of Organizational Change Management, 20(4), 509-524.

Fornell, C., \& Bookstein, F. L. (1982), Two Structural Equation Models: LISREL and PLS Applied to Consumer Exit-Voice Theory, Journal of Marketing Research, 19(4), 440-452.

Fornell, C. \& Larcker, D. F. (1981). Evaluating structural equation models with 
unobservable variables and measurement error, Journal of Marketing Research, 18(1), 39-50.

French, E., \& Delahaye, B. (1996). Individual change transition: Moving in circles can be good for you, Leadership \& Organization Development Journal, 17(7), 22-28.

Garthwaite, P.H. (1994). An interpretation of partial least squares, Journal of the American Statistical Association, 89, 122-127

Geisser, S. (1975). The predictive sample reuse method with applications, Journal of the American Statistical Association, 70, 320-328.

Gupta, A., \& Govindarajan, V. (2000). Knowledge flows within MNCs, Strategic Management Journal, 21(4), 473-496.

Harrington, S. J., \& Guimaraes, T. (2005). Corporate culture, absorptive capacity and IT success, Information and Organization, 15(1), 39-63.

Howard-Grenville, J. A. (2005). The persistence of flexible organizational routines: The role of agency and organizational context, Organization Science, 16(6), 618-636.

Huber, G. P. (1991). Organizational learning the contributing processes and the literatures, Organization Science, 2(1), 88-115.

Hulland, J. (1999). Use of partial least squares (PLS) in strategic management research: A review of four recent studies, Strategic Management Journal, 20(2), 195- 204.

Imai, K., Nonaka, I., \& Takeuchi, H. (1985). Managing the new product development process: How Japanese companies learn and unlearn. In: K. B. Clark, R. H. Hayes and C. Lorenz (eds.), The uneasy alliance: Managing the productivitytechnology dilemma. (pp. 337-375). Boston: Harvard Business School Press.

Jansen, J. J. P., Van Den Bosch, F. A. J., \& Volberda, H. W. (2005). Managing potential and realized absorptive capacity: How do organizational antecedents matter?, Academy of Management Journal, 48(6), 99-1015.

Kim, L. (1998). Crisis construction and organizational learning: Capability building in catching-up at Hyundai Motor, Organization Science, 9(4), 506-521.

Lane, P. J., \& Lubatkin, M. (1998). Relative absorptive capacity and interorganizational learning, Strategic Management Journal, 19(5), 461-477.

Leonard-Barton, D. (1992). Core capabilities and core rigidities: A paradox in managing new product development, Strategic Management Journal, 13(SI), $111-125$.

Levinthal, D., \& March, J. G. (1993). The myopia of learning, Strategic Management Journal, 14, 95-112.

Madorran-García, C., \& Val-Pardo, de I. (2006). An analysis of the strategies for public hospitals. Health Services Management Research, 19(4), 251-263.

Lewin, K. (1951). Field theory in social science, Harper, New York.

Lyndon, H. (1989). I did it my way! An introduction to "old way/new way" methodology, Australasian Journal of Special Education, 13(1), 32-37.

MacKenzie, P., Podsakoff, M., \& Jarvis, C. (2005). The problem of measurement model misspecification in behavioural and organizational research and some recommended solutions, Journal of Applied Psychology, 90(4), 710-730.

March, J. G. (1972). Model bias in social action, Review of Educational Research, 42(4), 413-429. 
Mathieson, K., Peacock, E., \& Chin, W. W. (2001). Extending the technology acceptance model: The influence of perceived user resources, The Data Base for Advances in Information Systems, 32(3), 86-112.

Mitchell, C. \& Sackney, L. (2000). Profound improvement: Building capacity for a learning community, Swets \& Zeitlinger, Lisse, Netherlands.

Montalto M. (1996). Patients' and careers's satisfaction with Hospital-in-the-Home Care. International Journal for Quality in Health Care, 8(3), 243-251.

Newey, L. R. \& Zahra, S. A. (2009). The evolving firm: How dynamic and operating capabilities interact to enable entrepreneurship, British Journal of Management, 20(1), 81-100.

Nonaka, I., Toyoma, R., \& Byosiere, P. A. (2001). Theory of organizational knowledge creation: understanding the dynamic process of creating knowledge. In: M. Dierkes, et al. (ed.) Handbook of Organizational Learning and Knowledge. New York: Oxford University Press.

Nunnally, J. C. (1978). Psychometric theory, McGraw-Hill, New York.

Nystrom, P. C., \& Starbuck, W. H. (1984). To avoid organizational crises, unlearn, Organizational Dynamics, 12(4), 53-65.

Planas-Miret, I., Tur-Prats, A., \& Puig-Junoy, J. (2005). Spanish health benefits for services of curative care. The European Journal of Health Economics, 6(1), 6672.

Podsakoff, P. M., MacKenzie, S. B., Lee, J.-Y., \& Podsakoff, N. P. (2003). Common method biases in behavioral research: A critical review of the literature and recommended remedies, Journal of Applied Psychology, 88(5), 879-903.

Purvis, R. L., Sambamurthy, V. \& Zmud, R. W. (2001). The assimilation of knowledge platforms in organizations: an empirical investigation, Organization Science, $12(2), 117-135$.

Reason, J. (1997). Managing the risks of organizational accidents, Aldershot, Ashgate.

Rebernik, M., \& Sirec, K. (2007). Fostering innovation by unlearning tacit knowledge, Kybernetes, 36(3/4), 406-419.

Rushmer, R., \& Davies, H.T. (2004). Unlearning in health care. Quality Safety Health Care, 13(2), 10-15.

Shaw, R. B., \& Perkins, D. N. (1991). Teaching organizations to learn, Organization Development Journal, 9(4), 1-12.

Sinkula, J. M. (1994). Market information processing and organizational learning, Journal of Marketing, 58(1), 35-45.

Sinkula, J. M. (2002). Market-based success, organizational routines, and unlearning, Journal of Business \& Industrial Marketing, 17(4), 253-269.

Sinkula, J. M., Baker, W. E. \& Noordewier, T. (1997). A framework for market-based organizational learning: Linking values, knowledge and behaviour, Journal of the Academy of Marketing Science, 25(4), 305-318.

Slater, S. F., \& Narver, J. C. (1995). Market orientation and the learning organization, Journal of Marketing, 59(3), 63-74.

Stone, M. (1974). Cross-validatory choice and assessment of statistical predictions, Journal of the Royal Statistical Society, 36(2), 111-147. 
Swee, C.G. (2002). Managing effective knowledge transfer: an integrative framework and some practice implications. Journal of Knowledge Management, 6(1), 23-30.

Tippins, M. J., \& Sohi, R. S. (2003). IT competency and firm performance: Is organizational learning a missing link, Strategic Management Journal, 24(8), 745-761.

Toft, B., \& Reynolds, S. (1994). Learning from disasters. A management approach, Butterworth-Heinemann, Oxford.

Tripsas, M., \& Gavetti, G. (2000). Capabilities, cognition, and inertia: Evidence from digital imaging, Strategic Management Journal, 21(10-11), 1147-1162.

Tsai, W. (2001). Knowledge transfer in intraorganizational networks: Effects of network position and absorptive capacity on business unit innovation and performance, Academy of Management Journal, 44(5), 996-1004.

Tsang, E., \& Zabra, S. (2008). Organizational unlearning, Human Relations, 61(10), 1435-1462.

Wenger, E. (1998). Communities of practice: Learning, meaning and identity, Cambridge University Press., Cambridge, UK.

Wold, H. (1966). Estimation of principal components and related models by iterative least squares. In P.R. Krishnaiaah (Ed.). Multivariate Analysis. (pp. 391-420) New York: Academic Press

Wold, H. (1985). Partial least squares. In S. Kolz and N. L, Johnson (Ed.), Encyclopedia of Statistical Sciences (Vol. 6, pp. 581-591). New York: Wiley.

Zahra, S. A., \& George, G. (2002). Absorptive capacity: A review, reconceptualization, and extension, Academy of Management Review, 27(2), 185-203. 
TABLE 1: Factor Loadings of reflective constructs

\begin{tabular}{|c|c|c|c|c|c|c|c|}
\hline & TRANSFORM & EXPLOITATION & ADQUISITION & ASSIMILATION & UNDERSTANDINGS & LENS & $\begin{array}{c}\text { INDIV. } \\
\text { HABITS }\end{array}$ \\
\hline P10_1 & 0.81 & 0.47 & 0.54 & 0.48 & 0.43 & 0.40 & 0.37 \\
\hline P10_2 & 0.81 & 0.56 & 0.40 & 0.40 & 0.44 & 0.41 & 0.32 \\
\hline P10_3 & 0.79 & 0.69 & 0.38 & 0.32 & 0.40 & 0.33 & 0.33 \\
\hline P10_7 & 0.62 & 0.86 & 0.48 & 0.41 & 0.53 & 0.39 & 0.40 \\
\hline P10_10 & 0.51 & 0.82 & 0.51 & 0.46 & 0.44 & 0.29 & 0.50 \\
\hline P10_12 & 0.61 & 0.79 & 0.32 & 0.35 & 0.45 & 0.33 & 0.36 \\
\hline P9_1 & 0.45 & 0.39 & 0.79 & 0.63 & 0.39 & 0.46 & 0.49 \\
\hline P9_3 & 0.43 & 0.42 & 0.77 & 0.33 & 0.44 & 0.31 & 0.36 \\
\hline P9_5 & 0.34 & 0.39 & 0.74 & 0.40 & 0.36 & 0.16 & 0.27 \\
\hline P9_8 & 0.56 & 0.54 & 0.63 & 0.94 & 0.50 & 0.48 & 0.57 \\
\hline P9_9 & 0.22 & 0.24 & 0.34 & 0.75 & 0.28 & 0.31 & 0.35 \\
\hline P9_10 & 0.44 & 0.42 & 0.53 & 0.93 & 0.50 & 0.50 & 0.48 \\
\hline P5_1 & 0.50 & 0.58 & 0.53 & 0.45 & 0.88 & 0.49 & 0.57 \\
\hline P5_2 & 0.46 & 0.51 & 0.53 & 0.42 & 0.74 & 0.34 & 0.60 \\
\hline P5_3 & 0.53 & 0.49 & 0.40 & 0.50 & 0.75 & 0.45 & 0.60 \\
\hline P5_4 & 0.42 & 0.45 & 0.40 & 0.45 & 0.87 & 0.51 & 0.60 \\
\hline P5_5 & 0.41 & 0.41 & 0.39 & 0.43 & 0.86 & 0.46 & 0.59 \\
\hline P5_6 & 0.35 & 0.40 & 0.31 & 0.39 & 0.81 & 0.41 & 0.60 \\
\hline P6_1 & 0.47 & 0.38 & 0.36 & 0.37 & 0.34 & 0.78 & 0.45 \\
\hline P6_2 & 0.37 & 0.33 & 0.34 & 0.34 & 0.38 & 0.77 & 0.46 \\
\hline P6_3 & 0.32 & 0.24 & 0.35 & 0.36 & 0.39 & 0.77 & 0.36 \\
\hline P6_4 & 0.38 & 0.36 & 0.38 & 0.50 & 0.52 & 0.87 & 0.45 \\
\hline P6_5 & 0.39 & 0.35 & 0.36 & 0.50 & 0.53 & 0.89 & 0.47 \\
\hline P7_1 & 0.34 & 0.43 & 0.44 & 0.51 & 0.62 & 0.44 & 0.88 \\
\hline P7_2 & 0.30 & 0.40 & 0.42 & 0.44 & 0.48 & 0.36 & 0.79 \\
\hline P7_3 & 0.40 & 0.50 & 0.51 & 0.46 & 0.59 & 0.45 & 0.85 \\
\hline P7_4 & 0.26 & 0.41 & 0.39 & 0.42 & 0.47 & 0.27 & 0.69 \\
\hline P7_5 & 0.43 & 0.44 & 0.44 & 0.54 & 0.66 & 0.51 & 0.91 \\
\hline P7_6 & 0.39 & 0.43 & 0.44 & 0.50 & 0.63 & 0.53 & 0.92 \\
\hline P7_7 & 0.38 & 0.41 & 0.45 & 0.48 & 0.61 & 0.49 & 0.85 \\
\hline
\end{tabular}


TABLE 2: Descriptive Statistics and Correlation Matrix

\begin{tabular}{|c|c|c|c|c|c|c|c|c|c|c|c|c|c|c|c|}
\hline & Mean $^{\mathrm{a}}$ & $\mathrm{SD}$ & $\mathrm{CA}$ & $\mathrm{CR}$ & AVE & 1 & $1 \mathrm{a}$ & $1 b$ & 2 & $2 \mathrm{a}$ & $2 b$ & $2 c$ & 3 & $3 a$ & $3 b$ \\
\hline 1. Potential Absorptive Capacity & 5.37 & 1.23 & n.a. & n.a. & n.a. & n.a. & & & & & & & & & \\
\hline 1a. Acquisition ${ }^{\mathrm{b}}$ & 5.48 & 1.25 & 0.78 & 0.71 & 0.54 & n.a. & 0.73 & & & & & & & & \\
\hline 1b Assimilation ${ }^{b}$ & 5.28 & 1.21 & 0.96 & 0.86 & 0.89 & n.a. & 0.63 & 0.94 & & & & & & & \\
\hline 2. Unlearning Context & 5.71 & 1.11 & n.a. & n.a. & n.a. & 0.67 & 0.59 & 0.62 & n.a. & & & & & & \\
\hline 2a. Consolidation of emergent $\mathrm{u} . \mathrm{b}^{\mathrm{b}}$ & 5.69 & 1.30 & 0.94 & 0.92 & 0.72 & 0.58 & 0.52 & 0.52 & n.a. & 0.76 & & & & & \\
\hline $2 b$. The examination of lens fitting ${ }^{b}$ & 6.04 & 0.90 & 0.91 & 0.88 & 0.67 & 0.53 & 0.44 & 0.51 & n.a. & 0.54 & 0.81 & & & & \\
\hline 2c. The framework for changing $i \ldots{ }^{b}$ & 5.40 & 1.10 & 0.96 & 0.95 & 0.78 & 0.61 & 0.52 & 0.56 & n.a. & 0.50 & 0.53 & 0.88 & & & \\
\hline 3. Realized Absorptive Capacity & 5.16 & 1.20 & n.a. & n.a. & n.a. & 0.60 & 0.59 & 0.54 & 0.62 & 0.57 & 0.47 & 0.51 & n.a. & & \\
\hline 3a. Transformation ${ }^{\mathrm{b}}$ & 4.94 & 1.14 & 0.84 & 0.78 & 0.65 & 0.57 & 0.54 & 0.49 & 0.57 & 0.52 & 0.46 & 0.42 & n.a. & 0.75 & \\
\hline 3b. Exploitation ${ }^{\mathrm{b}}$ & 5.39 & 1.26 & 0.86 & 0.84 & 0.68 & 0.57 & 0.52 & 0.49 & 0.59 & 0.57 & 0.41 & 0.50 & n.a. & 0.72 & 0.75 \\
\hline
\end{tabular}

Notes:

${ }^{\text {a }}$ Mean $=$ the average score for all of the items included in this measure; S.D. $=$ Standard Deviation; CA = Cronbach's Alpha; CR = Composite Reliability; AVE = Average

Variance Extracted; n.a. = not applicable. ${ }^{\mathrm{b}}$ They represent the dimensions of each second-order construct. The bold numbers on the diagonal are the square root of the Average Variance Extracted. Off-diagonal elements are correlations among constructs. 
TABLE 3: Weights of formative constructs

\begin{tabular}{lcc} 
High order constructs and their dimensions & weights & t de Student \\
\hline Potential Absorptive Capacity & 0.57 & 3.70 \\
Acquisition & 0.54 & 3.32 \\
Assimilation & & \\
Unlearning Context & 0.52 & 3.54 \\
Consolidation of emergent understandings & 0.32 & 2.96 \\
The examination of lens fitting & 0.32 & 2.92 \\
The framework for changing individual habits & & \\
Realized Absorptive Capacity & & 3.30 \\
Transformation & & \\
Exploitation & & \\
\end{tabular}


TABLE 4: Model statistics

\begin{tabular}{|c|c|c|c|c|c|}
\hline Hypothesis & $\begin{array}{l}\text { Path } \\
\text { coefficients }\end{array}$ & $\mathrm{T}$ values & $\mathrm{R}^{2}$ & $\Delta \mathrm{R}^{2}$ & $\mathrm{~F}^{2}$ \\
\hline $\begin{array}{l}\text { Potential absorptive capacity } \rightarrow \text { Realized absorptive } \\
\text { capacity (only direct effect) }\end{array}$ & $0.633^{* * *}$ & 7.17 & 0.40 & & \\
\hline $\begin{array}{l}\text { Potential absorptive capacity } \rightarrow \text { Realized absorptive } \\
\text { capacity (mediated by unlearning context) }\end{array}$ & $0.370^{* *}$ & 2.87 & 0.48 & +0.08 & 0.15 \\
\hline
\end{tabular}

$* * * \mathrm{p}<.001, * * \mathrm{p}<.01, * \mathrm{p}<.05, \mathrm{~ns}=$ not significant (based on a Student $\mathrm{t}$ (499) distribution with two tails). $\mathrm{t}(.001,499)=3.310124157, \mathrm{t}(.01,499)=2.585711627, \mathrm{t}(.05,499)=1.964726835$. 
FIGURE 1: The interaction between relearning and unlearning processes

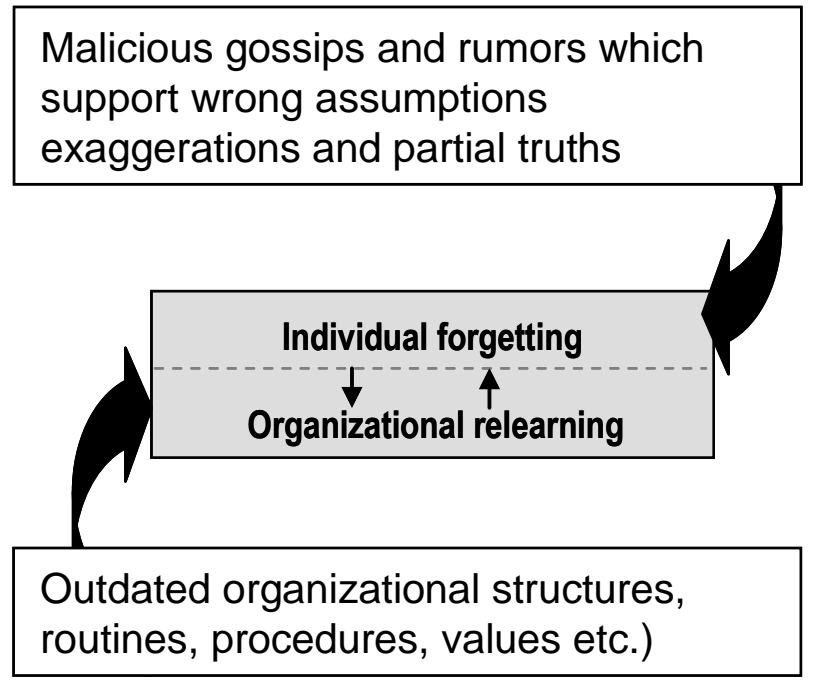

35 
Figure 2: Model and hypothesis

Para ver esta película, debe un descompresor. 
Figure 3: Estimated casual relationships in the structural model

(A) Model with direct effect

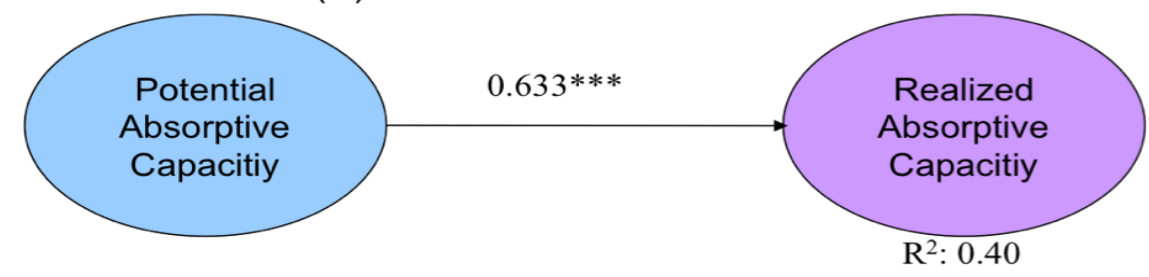

(B) Model with mediating effect

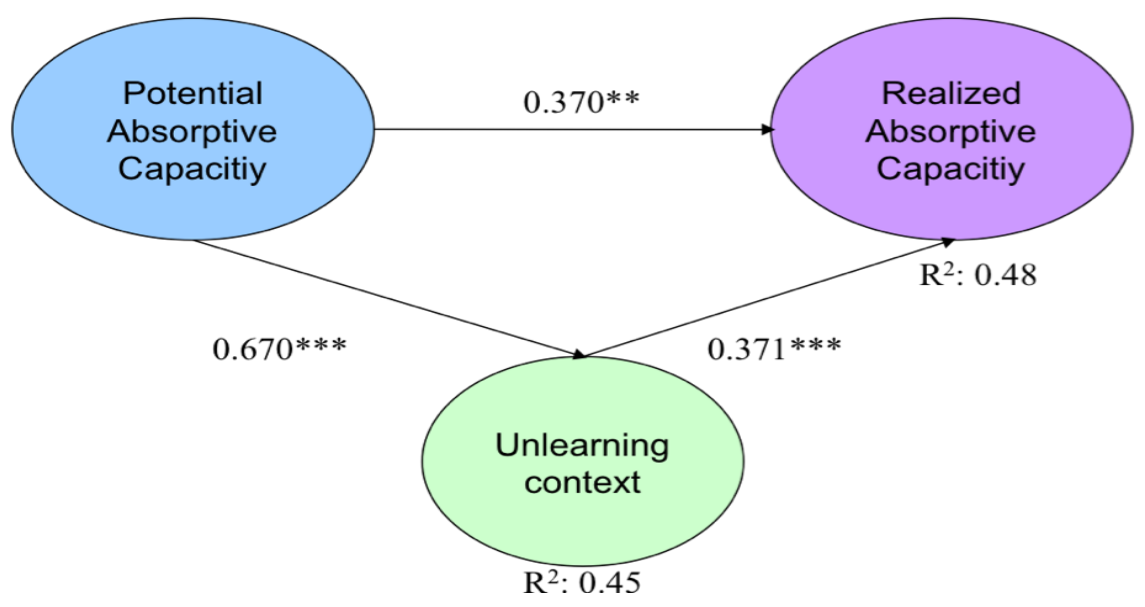

${ }^{*} \mathrm{p}<0.05 ; * * \mathrm{p}<0.01 ; * * * \mathrm{p}<0.001$ (based on $\mathrm{t}_{(499)}$, two-tailed test) 
Appendix 1. Questionnaire items

Potential Absorptive Capacity (1= high disagreement and 7= high agreement):

P9_1: Our unit has frequent interactions with hospital headquarters to acquire new knowledge

P9_2: Employees of our unit regularly visit other hospital areas

P9_3: We collect hospital information through informal means (e.g. lunch with hospital friends, talks with partners).

P9_4: Other divisions of our hospital are hardly visited (reversed).

P9_5: Our unit periodically organises special meeting with drug vendors or third parties to acquire new knowledge.

P9_6: Employees regularly approach third parties such as accountants, consultants or tax consultants

P9_7: We are slow to recognise shifts in our market (e.g. new treatment, regulation, demography) (reversed).

P9_8: New opportunities to serve our patients are quickly understood

P9_9: We quickly analyze and interpret changing patient demands

(Source: Jansen et al., 2005)

Realised Absorptive Capacity (1= high disagreement and 7= high agreement):

P10_1: Our unit regularly considers the consequences of changing market demands in terms of new ways to provide services

P10_2: Employees record and store newly acquired knowledge for future reference

P10_3: Our unit quickly recognises the usefulness of new external knowledge to existing knowledge

P10_4: Employees hardly share practical experiences (reverse)

P10_5: We laboriously grasp the opportunities for our unit from new external knowledge (reverse)

P10_6: Our unit periodically meets to discuss consequences of market trends an new services development

P10_7: Its clearly known how activities within our unit should be performed

P10_8: Patient complaints fall on deaf ears in our unit (reverse)

P10_9: Our unit has a clear division of roles and responsibilities

P10_11: We constantly consider how to better exploit knowledge

P10_12: Our unit has difficulty implementing new services (reverse)

P10_13: Employees have a common language regarding our services

(Source: Jansen et al., 2005)

The consolidation of emergent understandings: with respect to your organization indicate the degree of agreement or disagreement

(1= high disagreement and $7=$ high agreement):

P5_1: Managers seem to be open to new ideas and new ways of doing things

P5_2: Management has tried to initiate projects

P5_3: Managers recognise the value of new information, assimilate it and apply it

P5_4: Managers adopt the suggestions of personnel in the form of new routines and processes

P5_5: Managers are prone to collaborate with members of the hospital and to solve problems together

P5_6: Managers are concerned with the fact that the manner of answering before unforeseen circumstances will be known by all

(Source: Cegarra and Sánchez, 2008)

The examination of lens fitting: with respect to your current position indicate the degree of agreement or disagreement $(1=$ high disagreement and $7=$ high agreement):

P6_1: Employees are able to identify problems (new ways of doing things) easily

P6_2: Employees are able to see mistakes from my colleagues 
P6_3: Employees are able to listen to my patients (e.g. complaints, suggestions)

P6_4: Employees are able to share information with my boss easily

P6_5: Employees try to reflect and learn from their own mistakes

(Source: Cegarra and Sánchez, 2008)

The framework for changing the individual habits: with respect to your personal skills indicate the degree of agreement or disagreement (1= high disagreement and $7=$ high agreement):

P7_1: New situations have helped individuals identify their own mistakes

P7_2: New situations have helped individuals recognise unwished attitudes

P7_3: New situations have helped individuals identify improper behaviours

P7_4: Individuals recognise forms of reasoning or arriving to solutions as inadequate

P7_5: New situations have helped individuals change their behaviours

P7_6: New situations have helped individuals change their attitudes

P7_7: New situations have helped individuals change their thoughts

(Source: Cegarra and Sánchez, 2008) 